\title{
Bladder Cancer pT2 TNM Finding v6
}

National Cancer Institute

\section{Source}

National Cancer Institute. Bladder Cancer PT2 TNM Finding v6. NCI Thesaurus. Code C61210.

Bladder cancer with invasion into the muscle layer. (from AJCC 6th Ed.) 